\title{
Dynamic right ventricular outflow tract obstruction caused by a large interventricular membranous septal aneurysm
}

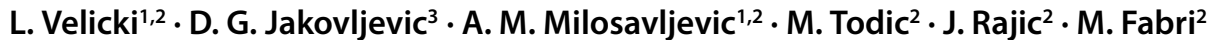

Published online: 23 August 2018

(c) The Author(s) 2018

A 60-year-old female patient was evaluated for progressive dyspnoea. Twenty-six years ago, the patient underwent atrial septum defect closure and pulmonary valve commissurotomy.

Transthoracic echocardiography showed preserved left heart function with normal endocavitary dimensions and moderate aortic regurgitation (pressure half time $320 \mathrm{~ms}$, vena contracta $0.6 \mathrm{~cm}$, regurgitant volume $0.5 \mathrm{ml}$, effective regurgitant orifice area $0.25 \mathrm{~cm}^{2}$ ). Echocardiography demonstrated increased velocity (maximal $4.8 \mathrm{~m} / \mathrm{s}$, velocity time integral $122.1 \mathrm{~cm}$ ) with pressure gradients (maximal $92 \mathrm{~mm} \mathrm{Hg}$, mean $38 \mathrm{~mm} \mathrm{Hg}$ ) over the right ventricular outflow tract (RVOT), which was narrowed to $0.8 \mathrm{~cm}$. Transoesophageal echocardiography established the cause of the RVOT obstruction: a large $(3 \times 2 \mathrm{~cm})$ interventricular membranous septal aneurysm (IMSA) causing dynamic infundibular obstruction (Fig. 1, and Video 1 and 2). The patient underwent aortic valve replacement and transaortic plication of the IMSA with two pledgeted sutures.

Dynamic systolic RVOT obstruction is one of the most unusual complications associated with IMSA with only a few cases reported so far [1-5].

Electronic supplementary material The online version of this article (https://doi.org/10.1007/s12471-018-1150-0) contains supplementary material, which is available to authorized users.

$\triangle$ L. Velicki

lazar.velicki@mf.uns.ac.rs

1 Faculty of Medicine, University of Novi Sad, Novi Sad, Serbia

2 Institute of Cardiovascular Diseases Vojvodina, Clinic for Cardiovascular Surgery, Sremska Kamenica, Serbia

3 Faculty of Medical Sciences, Newcastle University and Newcastle upon Tyne Hospitals NHS Foundation Trust, Newcastle upon Tyne, UK
Funding This study was supported by the Serbian Ministry of Education, Science and Technological Development (III41007, ON174028)

Conflict of interest L. Velicki, D.G. Jakovljevic, A.M. Milosavljevic, M. Todic, J. Rajic and M. Fabri declare that they have no competing interests.

Open Access This article is distributed under the terms of the Creative Commons Attribution 4.0 International License (http:// creativecommons.org/licenses/by/4.0/), which permits unrestricted use, distribution, and reproduction in any medium, provided you give appropriate credit to the original author(s) and the source, provide a link to the Creative Commons license, and indicate if changes were made.

\section{References}

1. Denault AY, Chaput M, Couture P, et al. Dynamic right ventricular outflow tract obstruction in cardiac surgery. J Thorac Cardiovasc Surg. 2006;132:43-9.

2. Vidne BA, Subramanian S, Wagner HR. Aneurysm of the membranous ventricular septum in transposition of the great arteries. Circulation. 1976;53:157-61.

3. Altunbas G, Gokaslan G, Ercan S, et al. Contribution of giant aneurysm of a membranous ventricular septal defect to right ventricular outflow tract obstruction. Thorac Cardiovasc Surg. 2013;61:320-2.

4. Chen SY, Chan KL, Beauchesne LM. Right ventricular outflow tract obstruction secondary to a membranous ventricular septal aneurysm. Eur J Echocardiogr. 2011;12:886.

5. Baweja G, Nanda NC, Nekkanti R, et al. Three-dimensional transesophageal echocardiographic delineation of ventricular septal aneurysm producing right ventricular outflow obstruction in an adult. Echocardiography. 2004;21:95-7. 

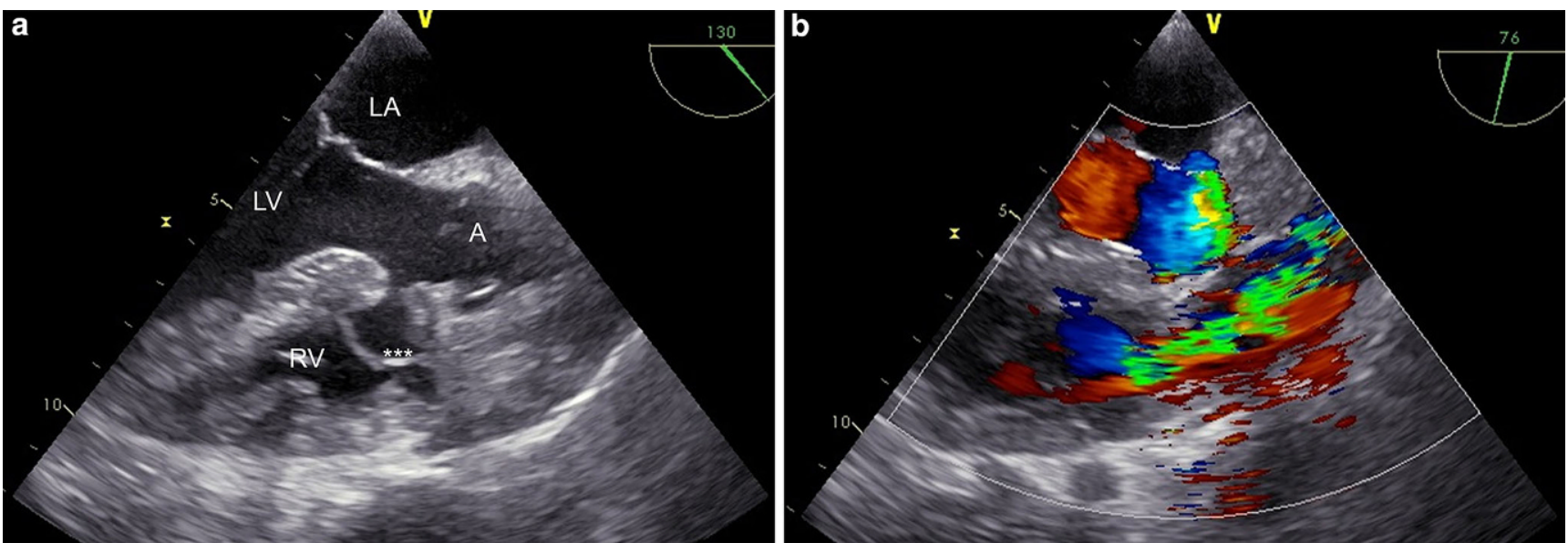

Fig. 1 Transoesophageal echocardiography. a Membranous septum aneurysm dynamically obstructing RVOT during systole. See also online videos; b RVOT Doppler tracings showing signs of stenosis (maximal gradient $92 \mathrm{~mm} \mathrm{Hg}$, mean gradient $38 \mathrm{~mm} \mathrm{Hg}$ ). ( $L A$ left atrium, $L V$ left ventricle, $A$ aorta, $R V$ right ventricle. ${ }^{* * *}$ Interventricular membranous septal aneurysm) 